\title{
An Integrated Approach to Identify Low-Flammability Plant Species for Green Firebreaks
}

\author{
Brad R. Murray $\left.{ }^{1, *} \mathbb{(}\right)$, Colin Brown ${ }^{2}$, Megan L. Murray ${ }^{1}$, Daniel W. Krix ${ }^{1}$, Leigh J. Martin ${ }^{1}{ }^{1}$, \\ Thomas Hawthorne ${ }^{1}$, Molly I. Wallace ${ }^{1}$, Summer A. Potvin ${ }^{1}$ (D) and Jonathan K. Webb ${ }^{1}$ \\ 1 School of Life Sciences, University of Technology Sydney, PO Box 123, Ultimo, NSW 2007, Australia; \\ megan.murray@uts.edu.au (M.L.M.); daniel.krix@uts.edu.au (D.W.K.); leigh.martin@uts.edu.au (L.J.M.); \\ thomas.hawthorne@student.uts.edu.au (T.H.); molly.wallace@student.uts.edu.au (M.I.W.); \\ summerpotvin@gmail.com (S.A.P.); jonathan.webb@uts.edu.au (J.K.W.) \\ 2 NSW Rural Fire Service, Blaxland Rural Fire Brigade, NSW 2774, Australia; col@bluemtns.com \\ * Correspondence: brad.murray@uts.edu.au
}

Received: 7 April 2020; Accepted: 16 April 2020; Published: 18 April 2020

\begin{abstract}
With recent and predicted increases in the frequency and intensity of wildfires, there is a pressing need for mitigation strategies to reduce the impacts of wildfires on human lives, infrastructure and biodiversity. One strategy involves the use of low-flammability plants to build green firebreaks at the wildland-urban interface. It is common, however, to encounter uncertainty in a diverse range of stakeholders about the concept of flammability as it applies to plants, which may impede efforts to identify suitable low-flammability plant species. Here, we provide an approach to identify low-flammability plant species that integrates three fundamental and relatively easy-to-measure plant-flammability attributes - ignitibility, sustainability and combustibility - in a way that removes confusion about the concept of plant flammability. These three intrinsic flammability attributes relate to each other such that an ideal low-flammability species is one that is slow to ignite, sustains burning for a short period of time and combusts with low intensity. Consideration is then given to secondary attributes of plants critical to the selection of low-flammability plants, including attributes that influence the volume of fuel available for fires and the vertical and horizontal spread of fires. More work is urgently needed across the world to identify low-flammability plant species using standardised measurement protocols, and our integrated approach provides a transparent way to ensure we are selecting the right species, for the right location, in green firebreaks.
\end{abstract}

Keywords: combustibility; firebreak; flammability; ignitibility; plant traits; sustainability; wildland-urban interface

Australia experienced extraordinary wildfires across vast tracts of the landscape during the summer of 2019-2020 [1]. The loss of human lives, the destruction of homes and the ecological consequences for native biodiversity can only be described as catastrophic [2]. This wildfire event has brought to the fore discussions about what might be done to lower the risks of such impacts from future wildfires [3], particularly in the wildland-urban interface (WUI). The WUI covers areas of the landscape where human populations and their homes and infrastructure are in the closest proximity to natural vegetation. Given that the WUI is the frontline of human-wildfire interactions across the world, it is a primary target for the application of mitigation strategies to reduce such wildfire risks [4].

The WUI contains low-level urban development nested within a broader region of mostly natural wildland vegetation [5]. To protect lives, homes and infrastructure at the WUI, the strategic selection of low-flammability plants to build green firebreaks $[6,7]$ is a landscape approach that has the potential to slow or stop the progress of wildfires [8]. In wide-ranging discussions with colleagues, land managers and home garden enthusiasts, however, we commonly encountered confusion about the concept of 
flammability as it applies to plants. As a consequence, there is uncertainty about how to identify the most appropriate low-flammability plant species in any given setting. Such uncertainty most likely contributes to some species (e.g., Dodonea viscosa) being described as low-flammability in one source [9] while listed as high-flammability in another [10]. Therefore, our aim in this perspective piece is to provide an approach that integrates three fundamental measures of plant flammability to identify low-flammability plant species, in a way that removes confusion about the concept of plant flammability, when considering plant species for firebreaks at the wildland-urban interface. Our approach uses relatively easy-to-measure plant-flammability attributes and provides clarity with regard to what each attribute represents in terms of the potential for fire spread.

Plant flammability can be measured in a number of ways [11]. We suggest that there are three flammability properties in particular that need to be considered together when seeking to identify low-flammability plant species for green firebreaks. These properties include how much time it takes for a plant to ignite (ignitibility), the length of time over which a plant burns (sustainability) and how well a plant burns (combustibility) [12]. Ignitibility, sustainability and combustibility describe what can be referred to as intrinsic flammability attributes, as they characterise the primary burning properties of plants. Variation in these three flammability attributes is driven by plant traits including, among others, fuel-moisture content, leaf mass per area, leaf-dry-matter content and volatile compounds $[13,14]$.

Here, we demonstrate that understanding how ignitibility, sustainability and combustibility relate to each other provides an opportunity, via a functionally integrated approach, to identify potential 'ideal' low-flammability plant species (Figure 1). For an ideal low-flammability plant species, as shown in the hypothetical scenario in Figure 1, the flammability attributes relate to each other such that the species is slow to ignite, sustains burning for a short period of time and combusts with low intensity (species colour-coded in blue). In contrast, species that ignite quickly, burn for a long time and burn with high intensity are the most flammable and 'non-ideal' species (species colour-coded in red). Measuring the ignitibility, sustainability and combustibility of a wide range of species and comparatively assessing the relationships among these three attributes provides the first step in identifying both the ideal low-flammability plant species for green firebreaks and, at the same time, the most flammable species that should be avoided.

Using ignitibility and sustainability to identify low-flammability species is important because time is a critical consideration during wildfire events at the WUI. In terms of ignitibility, a species that takes a long time to ignite may eventually either not ignite at all, which can help to stop the spread of wildfires, or it can provide badly needed time for fire-fighting activities such as putting out spot fires around properties from ember attacks. With respect to sustainability, a species that ignites but which does not burn for a long period of time further restricts the opportunities for wildfires to spread. Combustibility is similarly an important measure of plant flammability because species that burn with low intensity and emit low heat will be critical in slowing down or even preventing the spread of wildfires.

Once a thorough appreciation of the nature of the relationships among plant ignitibility, sustainability and combustibility has been obtained, consideration needs to be given to secondary attributes of plants - beyond the intrinsic flammability properties - that contribute to fire behaviour, so as to refine the selection of low-flammability plant species for firebreaks. The types of secondary attributes that need to be considered are those that influence the volume of fuel available for fires and which contribute to the vertical and horizontal spread of fires. These include volume of litter produced, presence of decorticating barks, plant-bulk density and ember production $[15,16]$. With respect to these secondary attributes, low-flammability plant species are distinguished by the production of low quantities of litter fuel, possession of non-decorticating bark, the ability to store water and to not dry out quickly, having low-bulk density and having the production of few (or no) embers likely to travel easily across large distances. Naturally, this level of understanding of plant flammability has the potential to be scaled up to the broader landscape and combined with information on vegetation attributes, such as standing crop and fuel-moisture content [17]. 


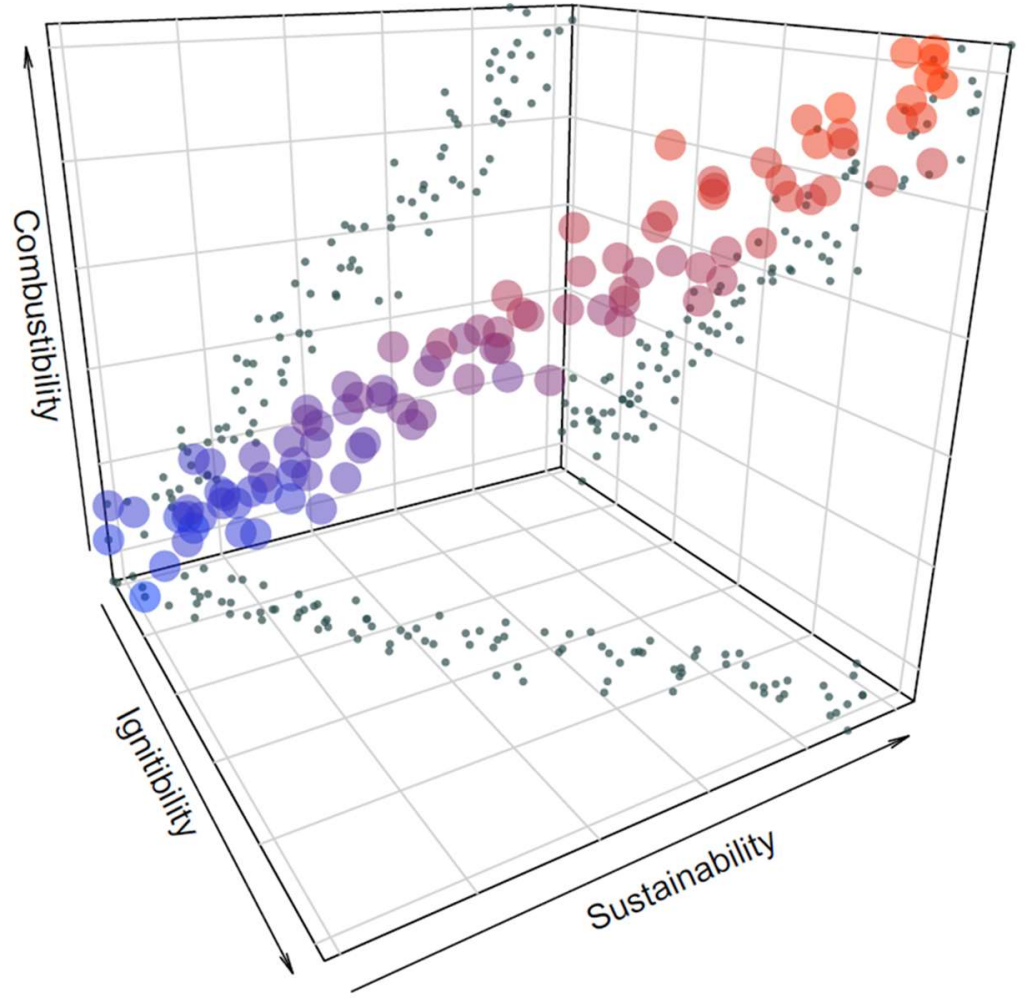

Figure 1. An integrated approach to identify low-flammability plant species using three intrinsic plant-flammability attributes. In this hypothetical scenario, each coloured circle represents the position of species based on relationships among ignitibility, sustainability and consumability. Ideal low-flammability species (blue) have slow ignitibility, short sustainability and low combustibility. Non-ideal high-flammability species (red) have fast ignitibility, long sustainability and high combustibility.

At present, there is limited information in the scientific literature to assess how these three flammability attributes relate to each other $[14,18,19]$. We urgently need more work across the world to determine the nature of these relationships so as to ensure we are selecting the right low-flammability species for the right location. Flammability research at the leaf scale has shown that sustainability and combustibility are correlated such that species that burn for short periods also have low combustibility, consistent with the characteristics of an ideal low-flammability species (60 plant species of fire-prone woodlands of eastern Australia [19]). However, in that study, ignitibility was negatively correlated with sustainability, such that species that did not burn for long were actually the quickest to ignite. At the scale of plant shoots, it is important to understand how this multidimensional relationship may be shaped by increased plant matter and increasingly complex plant architecture, as this will have important implications for assessing fire-wise plantings near domestic dwellings. At the shoot level, positive relationships were found between long sustainability and high combustibility [14], as well as fast ignitibility and high combustibility, however, as for the leaf level, there appears to be a decoupling between sustainability and ignitibility [18]. Importantly, standardised measurement protocols are essential moving forward to allow reliable comparability of low- and high-flammability species across the world. There is a range of techniques available for measuring plant flammability, spanning the flammability of small parts (e.g., discs) of leaves, to whole leaves to shoots and whole plants. In the context of green firebreaks, the seminal work by Jaureguiberry et al. (2011) [20], which described a device for the standard measurement of shoot flammability, appears to be gaining traction in work comparing the flammability of various plant species in a way that captures variation in plant architecture [14,18]. 
The early evidence that, in some cases, some pairs of flammability attributes (e.g., ignitibility and sustainability) do not align to produce ideal low-flammability species means that low-flammability species may need to be selected on the basis of a preferred flammability attribute. In other words, the ideal low-flammability species that possesses all three attributes at the low end of their flammability ranges may not exist in some circumstances. Here, species that ignite quickly might be selected because they do not burn for long and thus are unlikely to contribute to continued fire spread. In contrast, species that take a long time to ignite might be selected because they provide a longer window of time to extinguish flame, despite burning for a long time once alight. At this stage, it is not known how far down this path of trading off flammability attributes such as ignitibility and sustainability we need to progress, as the empirical evidence is not currently available. Much more plant flammability testing is required, and in situations where ideal low-flammability species cannot easily be identified, strategic decisions will need to be made as how to best deal with the trade-offs described above.

Author Contributions: Conceptualisation, B.R.M., D.W.K. and C.B.; writing-original draft preparation, B.R.M., M.L.M., D.W.K., L.J.M., T.H., M.I.W., S.A.P. and J.K.W.; writing-review and editing, B.R.M; visualisation, D.W.K. and B.R.M.; supervision, B.R.M. All authors have read and agreed to the published version of the manuscript.

Funding: This research received no external funding.

Acknowledgments: We thank Harry Sullivan for helpful discussions and support.

Conflicts of Interest: The authors declare no conflicts of interest.

\section{References}

1. Nolan, R.H.; Boer, M.M.; Collins, L.; de Dios, V.R.; Clarke, H.; Jenkins, M.; Kenny, B.; Bradstock, R.A. Causes and consequences of eastern Australia's 2019-20 season of mega-fires. Glob. Chang. Biol. 2020. [CrossRef] [PubMed]

2. Pickrell, J. Australia's vulnerable species hit hard by fires. Science 2019, 366, 1427-1428. [CrossRef] [PubMed]

3. Phillips, N.; Nogrady, B. The race to decipher how climate change influenced Australia's record fires. Nature 2020, 577, 610-612. [CrossRef] [PubMed]

4. Moritz, M.A.; Batllori, E.; Bradstock, R.A.; Gill, A.M.; Handmer, J.; Hessburg, P.F.; Leonard, J.; McCaffrey, S.; Odion, D.C.; Schoennagel, T.; et al. Learning to coexist with wildfire. Nature 2014, 515, 58-66. [CrossRef] [PubMed]

5. Michael, Y.; Lensky, I.; Brenner, S.; Tchetchik, A.; Tessler, N.; Helman, D. Economic assessment of fire damage to urban forest in the wildland-urban interface using planet satellites constellation images. Remote Sens. 2018, 10, 1479. [CrossRef]

6. Curran, T.J.; Perry, G.L.W.; Wyse, S.V.; Alam, M.A. Managing fire and biodiversity in the wildland-urban interface: A role for green firebreaks. Fire 2018, 1, 3. [CrossRef]

7. Murray, B.R.; Martin, L.J.; Brown, C.; Krix, D.W.; Phillips, M.L. Selecting low-flammability plants as green firebreaks within sustainable urban garden design. Fire 2018, 1, 15. [CrossRef]

8. Cui, X.; Alam, M.A.; Perry, G.L.W.; Paterson, A.M.; Wyse, S.V.; Curran, T.J. Green firebreaks as a management tool for wildfires: Lessons from China. J. Environ. Manag. 2019, 233, 329-336. [CrossRef] [PubMed]

9. Ozbreed. Fire Retardant Plants: Literature Review and Plant List. Available online: https://www.ozbreed. com.au/download/fire_retardant_plants.pdf (accessed on 9 March 2020).

10. TFS. Fire Retardant Garden Plants for the Urban Fringe and Rural Areas. Tasmania Fire Service. Available online: https://www.fire.tas.gov.au/publications/1709\%20Brochure.pdf (accessed on 9 March 2020).

11. Pérez-Harguindeguy, N.; Díaz, S.; Garnier, E.; Lavorel, S.; Poorter, H.; Jaureguiberry, P.; Bret-Harte, M.S.; Cornwell, W.K.; Craine, J.M.; Gurvich, D.E.; et al. New handbook for standardised measurement of plant functional traits worldwide. Aust. J. Bot. 2013, 61, 167-234. [CrossRef]

12. Anderson, H.E. Forest fuel ignitibility. Fire Technol. 1970, 6, 312-319. [CrossRef]

13. Murray, B.R.; Hardstaff, L.K.; Phillips, M.L. Differences in leaf flammability, leaf traits and flammability-trait relationships between native and exotic plant species of dry sclerophyll forest. PLoS ONE 2013, 8, 79205. [CrossRef] [PubMed] 
14. Alam, M.A.; Wyse, S.V.; Buckley, H.L.; Perry, G.L.W.; Sullivan, J.J.; Mason, N.W.H.; Buxton, R.; Richardson, S.J.; Curran, T.J. Shoot flammability is decoupled from leaf flammability, but controlled by leaf functional traits. J. Ecol. 2020, 108, 641-653. [CrossRef]

15. Gill, A.M.; Zylstra, P. Flammability of Australian forests. Aust. For. 2005, 68, 87-93. [CrossRef]

16. Schwilk, D.W. Dimensions of plant flammability. New Phytol. 2015, 206, 486-488. [CrossRef] [PubMed]

17. Sharma, S.; Ochsner, T.E.; Twidwell, D.; Carlson, J.D.; Krueger, E.S.; Engle, D.M.; Fuhlendorf, S.D. Nondestructive estimation of standing crop and fuel moisture content in Tallgrass Prairie. Rangel. Ecol. Manag. 2018, 71, 356-362. [CrossRef]

18. Wyse, S.V.; Perry, G.L.W.; Curran, T.J. Shoot-level flammability of species mixtures is driven by the most flammable species: Implications for vegetation-fire feedbacks favouring invasive species. Ecosystems 2018, 21, 886-900. [CrossRef]

19. Krix, D.W.; Phillips, M.L.; Murray, B.R. Relationships among leaf flammability attributes and identifying low-leaf-flammability species at the wildland-urban interface. Int. J. Wildland Fire 2019, 28, $295-307$. [CrossRef]

20. Jaureguiberry, P.; Bertone, G.; Diaz, S. Device for the standard measurement of shoot flammability in the field. Austral Ecol. 2011, 36, 821-829. [CrossRef]

(C) 2020 by the authors. Licensee MDPI, Basel, Switzerland. This article is an open access article distributed under the terms and conditions of the Creative Commons Attribution (CC BY) license (http://creativecommons.org/licenses/by/4.0/). 